\title{
Recent advances in $Q$ Theory: Segment strength
}

\author{
Martha Schwarz, Myriam Lapierre, Karee Garvin \& Sharon Inkelas*
}

\begin{abstract}
Using Q Theory, in which canonical segments are represented as a sequence of three subsegments, this paper develops a scale of vowel quantity, ranging from 'superlight' single v subsegments to 'heavy' or geminate vowels consisting of four subsegments. An Optimality-Theoretic analysis of quantitysensitive stress assignment is developed, in which stress is preferred on vowels with more subsegments. A case study of the Jê language Panãra demonstrates that a single language can draw a four-way vowel quantity contrast, to which the stress system is sensitive.
\end{abstract}

Keywords. segments, subsegments, Q Theory, quantity-sensitive stress, vowel length

1. Introduction. $Q$ Theory represents a segment $(\mathrm{Q})$ as a string of three temporally-ordered subsegments (q1 q2 q3) (Inkelas \& Shih 2013, 2016, 2017, Shih \& Inkelas 2014, 2019). With three subsegments, Q Theory can capture tripartite segments like triphthongs, triple-tone contours, and circum-oralized nasal stops. While contour segments necessitate at least three subsegments as the necessary level of representational granularity, Q Theory has the flexibility to vary this number, provided there is phonological motivation to do so. Working within Q Theory, this paper proposes representations that use varying numbers of subsegments in order to capture the variable phonological status and strength of segments. Building on work by Garvin, Lapierre, and Inkelas (2018), which discusses geminates as a case study for subsegmental representations with greater than 3 subsegments, this Q-Theoretic study brings the patterning of inserted segments to bear on the lower end of the scale, arguing that all points on the scale of 1-4 vocalic subsegments are needed to capture a range of quantity-sensitive vowel behavior, from excrescent vowels at the low end of the scale to phonologically long vowels at the high end. We embed these representations in a Optimality-Theoretic analysis, offering a proof by demonstration that the subsegmental scale can generate an observed typology of quantity-sensitive cross-linguistic and language-internal vowel behaviors.

2. Background. Building on insights from Aperture Theory and Articulatory Phonology (Browman \& Goldstein 1989, 1990, 1992; Steriade 1993), Q Theory proposes three subsegments as the necessary level of granularity to capture the behavior of contour segments (Inkelas \& Shih 2014, 2016; Shih \& Inkelas 2017, 2019; Garvin et al. 2018; see also Shih \& Inkelas (this volume). For instance, Dinka makes a distinction between early falling and late falling tones, which cannot be captured with two subsegments as both would be represented as HL (Remijsen 2013). In Q Theory, however, this is straightforwardly captured as (h 11 ) for early falling and (h h 1) for late falling. Prenasalized segments are another testing area for the necessary level of granularity for subsegmental representations. For instance, pre-nasalized affricates necessitate

\footnotetext{
* Thanks to the participants of the LSA 2019 Special Session 'Inside Segments', especially Ryan Bennett, Nancy Hall, John Kingston, and Donca Steriade; members of the Complex Segments Seminar at UC Santa Cruz; Anne Pycha; and the Panãra community. Authors: Martha Schwarz, Myriam Lapierre, Karee Garvin, \& Sharon Inkelas (University of California, Berkeley).
} 
three subsegments, e.g. (n d z) (cf. Steriade 1993). The pre- and post-oralization pattern demonstrated in Kaingang and Karitiâna (Wiesemann 1972, Storto 1999, and Garvin et al., 2018) further motivates the need for three subsegments to capture the phonological pattern of nasals across environments, where $(\mathrm{m} \mathrm{m} \mathrm{m}),(\mathrm{m} \mathrm{m} \mathrm{b}),(\mathrm{b} \mathrm{m} \mathrm{m})$, and $(\mathrm{b} \mathrm{m} \mathrm{b})$ all surface as allophones of $/ \mathrm{m} /$ depending on the oral and nasal quality of the vocalic environment. The crucial claim that these examples serve to illustrate is that the two-phase subsegmental representations proposed in Aperture Theory, while a great improvement over one-phase representations, are not sufficient to capture the full range of contour segments; Q Theory's greater subsegmental granularity is needed.

The three phases into which Q Theory divides canonical segments, which in certain cases can serve as an analogy to the articulatory landmarks posited to coordinate gestures in Articulatory Phonology, are: movement toward the target, achievement of the target, and release of the target (Browman \& Goldstein 1989, 1990, 1992). Q-Theoretic representations offer a quantized representation of these gestures, and in so doing offer an interface between the continuously valued gestural scores of Articulatory Phonology and the quantal, discrete representations that are useful in modeling more categorical morphophonemic alternations and cross-linguistic typological phonological patterns.

3. Subsegmental strength scales. While quantized tripartite representations for canonical consonants and vowels are clearly needed for three-phase contour segments and are a useful point of departure, Q Theory also has the potential to scale up or scale down the number of subsegments in a given segment, based on phonological evidence. That potential is the subject of this study.

3.1 SCALING UP: REPRESENTING GEMINATES. Garvin et al. (2018) explore the possibility of using four subsegments to represent geminated segments. As Garvin et al. (2018) observe, gemination generally consists of lengthening the articulatory target constriction (rather than the transition into, or the release) of a segment. To capture this asymmetry in Q Theory, Garvin et al. propose that gemination of a canonical intervocalic consonant consists of adding closure subsegments to that consonant, such that the result is a string of subsegments divided across two syllables, with closure subsegments on either side of the syllable boundary, e.g., $\left(\mathrm{t}^{1} \mathrm{t}^{2} \mathrm{t}^{3}\right)->\left(\mathrm{t}^{1} \mathrm{t}^{2} \cdot \mathrm{t}^{2} \mathrm{t}^{3}\right)$. Beyond merely capturing the lengthening of the closure in geminates, this representation is amenable to ambisyllabicity, intuitively the right syllabification for canonical intervocalic geminates but not straightforward to represent at the segmental level. While CV and Autosegmental Phonology can offer a doubled representation $(/ \mathrm{t} /->/ \mathrm{tt} /)$, such models do not automatically predict that the first half of the geminate is unreleased. In Q Theory, that follows from adding internal, target subsegments.

Garvin et al. (2018) further support this analysis of gemination with articulatory evidence from Pycha's richly detailed and insightful $(2009,2010)$ study of singleton and geminate affricates in Hungarian. Pycha showed that the Hungarian affricates [ts] and [t $\mathrm{f}$ ] differ in their internal relative timing: the frication portion of [ts] is longer than that of [t $\left.\int\right]$. Inkelas and Shih (2017) incorporate Pycha's insight about the singleton affricates into Q-Theoretic representations: ( $\mathrm{t} \mathrm{s} \mathrm{s}$ ) for [ts], and ( $\mathrm{t} \mathrm{t} \int$ ) for [t $\left.\int\right]$. Crucially, Pycha shows that this relative difference in timing across the two types of affricates is maintained under phonological lengthening (though not phonetic lengthening). This confirms that the relative internal timing pattern is phonologized, as per the $\mathrm{Q}$ Theory representations. 
The Q-Theoretic analysis of gemination proposed by Garvin et al. (2018) predicts, correctly, that the internal timing differences across [ts] and [t $\mathrm{t}]$ are preserved under gemination. According to Garvin et al., gemination consists of adding closure subsegments. Thus Hungarian [ts], or ( $\mathrm{s}$ $\mathrm{s}$ ) in Q Theory terms, geminates as ( $\mathrm{t} \mathrm{t} . \mathrm{t} \mathrm{s} \mathrm{s}$ ); by contrast, Hungarian [ $\mathrm{t} \int$ ], or ( $\mathrm{t} \mathrm{f}$ ), geminates as $(\mathrm{t} t . \mathrm{t} \mathrm{J}$ ). These representations capture the extension of the stop closure and the ambisyllabicity of the geminate. Furthermore, these representations build on the articulatory representations proposed for unreleased stops, where the portion of the geminate in the first syllable matches the representation for an unreleased stop, and the portion of the geminate in the second syllable is identical to the singleton affricate with the lengthened closure across the syllable boundary.

3.2 SCALING DOWN: REPRESENTING SHORT SEGMENTS. Extensions of Q Theory give rise to the question of what other types of phonological status and patterning can be captured by QTheoretic representations. While Garvin et al. (2018) provides representations for gemination, the current study focuses on representing segment strength and inserted segments. We propose quantized representations from one to four subsegments in length to capture segments which range from excrescent to phonologically long, and the phonological patterning of differing segment strength. The proposals in this study build on the suggestion, made in Inkelas and Shih $(2016,2017)$, that certain segments may contain fewer than three subsegments. One example familiar from Steriade's work on Aperture Theory and alluded to in the discussion of geminate consonants above, is the case of final unreleased consonants. Working within Aperture Theory, Steriade $(1993,1994)$ proposed that released stops, which normally would possess both a closure and a release aperture node, lose the release node in final position in languages where final stops are unreleased. When the release node is deleted, so are any distinctive features that belong only to it. Steriade uses this analysis to derive effects like the loss of aspiration and glottalization on Korean coda obstruents. Q Theory incorporates this analysis directly. An aspirated $/ \mathrm{t}^{\mathrm{h}} /$ is represented in $\mathrm{Q}$ Theory as $(\mathrm{t} \mathrm{t} \mathrm{h})$. The first $(\mathrm{t})$ subsegment represents movement toward the $[t]$ closure; the second $(\mathrm{t})$ subsegment represents achievement of the $[\mathrm{t}]$ closure. The third (h) subsegment represents the aspirated burst. Deleting the final (h) subsegment in coda position leaves behind ( $\mathrm{t}$ ), an unaspirated stop missing its final subsegment. (This is exactly the representation proposed for the first half of a true geminate by Garvin et al. 2018, as discussed just above.)

Inkelas and Shih (2017) expand upon this general idea by proposing that flaps, too, may also merit a representation with fewer than three subsegments. Lacking a steady state target, flaps (and other ballistic consonants) consist solely of movement toward followed by movement and away from the target, e.g. ( $\mathrm{s}$ ).

The present study continues this line of analysis, but with a focus on vowels instead of consonants. The remainder of this paper is organized as follows: Section 4 presents the proposed typology of vowel strength within a Q-Theoretic framework. Section 5 motivates a scalar representation of segment strength using subsegments. Section 6 discusses vowel strength and faithfulness. Section 7 discusses vowel strength and stressability, applying the proposed model to data from Panãra, and Section 8 provides a brief discussion.

4. Four degrees of subsegmental vowel quantity. By representing phonological differences at a greater level of granularity than current models of representations are able to capture, Q Theory offers a new way of scaling segments: in terms of the number of subsegments they contain. In 
this section, we show that this scale is useful in capturing a previously elusive range of distinctions among types of vowels.

A starting point for the study is the observation, made in work by both Hall (2006) and Gafos (2002), that there are two distinct types of inserted (non-underlying) vowels, which they term epenthetic and excrescent (or, for Hall, 'intrusive') vowels. ${ }^{1}$ Epenthetic vowels sometimes behave like lexical (underlying) vowels and sometimes do not; excrescent vowels are always distinguishable from lexical vowels. Table 1 below summarizes the properties Hall and Gafos ascribe to each type.

\begin{tabular}{|c|c|}
\hline Excrescent & Epenthetic \\
\hline - Result of low gestural overlap & - Result of an inserted vowel gesture \\
\hline $\begin{array}{c}\text { - Schwa, copy vowel, or quality } \\
\text { dependent on surrounding segments }\end{array}$ & $\begin{array}{c}\text { - May have a fixed quality other than } \\
\text { schwa }\end{array}$ \\
\hline $\begin{array}{c}\text { - Optional, variable duration, } \\
\text { disappear at fast speech rate }\end{array}$ & - Not dependent on speech rate \\
\hline - Phonologically invisible & - Phonologically visible \\
\hline
\end{tabular}

Table 1: Properties of excrescent vs. epenthetic vowels

In traditional representations, the potentially deficient phonological status of a segment is dependent on its status as inserted or underlying, and on the surface epenthetic vowels and full underlying vowels are indistinguishable. But because the differences between excrescent and epenthetic vowels are visible and relevant to the phonology, Hall (2006) argues that distinct representations are in fact required. Hall proposes representations for these vowel types that rely on the timing of articulatory phonology gestures.

In this section, we propose Q-Theoretic surface representations that offer the same granularity that Hall calls for, and which can interface with stringent Optimality-Theoretic markedness constraints to capture cross-linguistic typological generalizations about the phonological patterning of the vowel types in question.

Q Theory makes it possible to represent four different degrees of vowel strength by positing that vowels can consist of one, two, three, or four vocalic subsegments. As depicted in Table 2, we term these points on the strength scale 'superlight', 'light', 'full', and 'long', respectively. Four degrees of strength is sufficient to capture the three-way distinction among vowels that Hall and Gafos call attention to (excrescent, epenthetic, and full vowels), as well as the additional category of phonologically long vowels. We use these terms rather than 'epenthetic' and 'excrescent' here because we intentionally want representations in which vowel strength is apparent in the surface representation, and independent from its status as underlying or inserted.

\begin{tabular}{|c|c|}
\hline Vowel type & Q-Theoretic representation \\
\hline Superlight & v \\
\hline Light & $(\mathrm{v} \mathrm{v})$ \\
\hline Full & $(\mathrm{v} \mathrm{v} \mathrm{v)}$ \\
\hline Long & ( v v v v) \\
\hline
\end{tabular}

Table 2: Proposed Q-Theoretic representations of four vowel types

\footnotetext{
${ }^{1}$ Hall (2006) uses the term intrusive vowels to draw a parallel with intrusive stop consonants; we use Gafos's 'excrescent' term for convenience, but agree with Hall that the parallels are instructive.
} 
In sections 5 and 6 we show how these representations interact with OT markedness and faithfulness constraints to derive implicational typological patterns of vowel behavior. First, however, we illustrate the need for a four-way strength distinction with a case study from Panãra.

While it is certainly not the case that every language makes use of all four types of vowels presented in Table 2, we do predict that some languages may exhibit the whole range of vowel strength contrasts. We present Panãra (ISO code: kre), a Northern Jê language spoken in Central Brazil, as an example of a language exhibiting all of these contrasts. Panãra has four different types of vowels, each of which is illustrated in Table 3, along with the associated Q-Theoretic representations. (For a fully detailed description of the pattern, see Lapierre (2019).)

\begin{tabular}{|c|c|c|}
\hline \multirow{2}{*}{ Inserted } & $\mathrm{V}$ & $\begin{array}{l}/ \mathrm{kr \gamma} / \rightarrow[\mathrm{k \gamma r \gamma}] \text { thigh } \\
(\mathrm{kkk}) \gamma(\mathrm{s})(\gamma \gamma \gamma)\end{array}$ \\
\hline & (v v) & 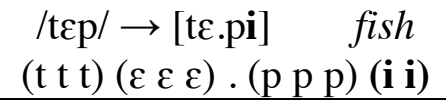 \\
\hline \multirow{2}{*}{ Underlying } & (v v v) & 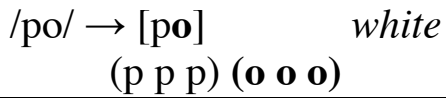 \\
\hline & $(\mathrm{V} V \mathrm{~V} v)$ & $\begin{array}{l}/ \text { po: } / \rightarrow \text { [po:] to arrive } \\
\quad(\text { p p p) (o o o o })\end{array}$ \\
\hline
\end{tabular}

Table 3: Typology of vowel strength contrasts observed in Panãra (Jê)

The first type of vowel, shown in the top row of Table 3, meets Hall's criteria for an excrescent vowel. It arises between stop-approximant clusters and its quality is entirely determined by its adjacent segments, suggesting that it is not the result of an independent gestural target. (This phenomenon, in other languages, has also been termed Dorsey's Law, and is discussed in more detail by Steriade (1999).) In Q-Theoretic terms, these vowels occupy the lowest point on the strength scale. Represented with a single v subsegment, they are 'superlight'. Note that these superlight vowels are represented notationally without parentheses, since they cannot serve as the nucleus of a syllable and thus do not constitute a segment on their own in Panãra.

The next type of vowel, shown in the second row of Table 3, is represented with two (v v) subsegments. Like the superlight vowels, these 'light' vowels are not present in the underlying form; they correspond to the category of 'epenthetic' in Hall's typology. Light vowels in Panãra are inserted to resolve a ban on word-final oral consonants (approximants and obstruents). Unlike superlight vowels, light vowels in Panãra have the consistent quality [i]. Like superlight vowels, light vowels can never bear stress, despite otherwise systematic final stress in the grammar of the language.

The third and fourth rows of Table 3 depict a minimal pair of 'full' ( $\mathrm{v} v \mathrm{v}$ ) and 'long' ( $\mathrm{v} \mathrm{v} \mathrm{v}$ v) vowels in Panãra. These are lexical vowels that differ in length. Unlike for light and superlight vowels, all vowel qualities in Panãra are available for full vowels. Both full and long vowels are able to bear stress.

Having illustrated a language that makes use of all four points on the vowel quantity scale, we turn next to developing a factorial typology within Optimality Theory in which the strength scale can interact with markedness constraints to generate predictions about vowel behavior. Section 5 discusses vowel strength and faithfulness; section 6 discusses vowel strength and stressability. 
5. Vowel strength and faithfulness. Cross-linguistically there is a clear correlation between a vowel's phonological strength and its lexical status. Q Theory captures this correlation in Optimality-Theoretic terms by embedding the vowel strength scale with phonological markedness and licensing constraints.

As is well known (see e.g., Hall 2003, 2006, 2011 for overviews), excrescent and epenthetic vowels tend to be short, or what we have termed 'superlight' or 'light' vowels, rather than full (vvv) or long (vVvv) vowels. Q Theory generates this alignment between lexical status and strength by scaling constraint violations by the number of subsegments involved. This can be accomplished formally in several ways. In this section on faithfulness constraints, we scale constraint penalties by the number of subsegments affected. In section 6 , we model scalar markedness by positing a family of (stringent) constraints, each of which is sensitive to subsegmental substrings of specific lengths.

Table 4 illustrates the result of scaling DEP to subsegmental quantity. As seen, DEP-q is violated once by the insertion of a superlight vowel (b), twice by the insertion of a light vowel, three times by the insertion of a full vowel, and four times by the insertion of a long vowel. Thus we predict that, all else being equal, inserted vowels will most commonly be on the lighter end of the spectrum. (Of course, markedness constraints can override this prediction in specific contexts where a full or long vowel might be required.)

\begin{tabular}{|c|c|c|c|}
\hline & /ket/ & *CODA & DEP-q \\
\hline a. & $(\mathrm{k} \mathrm{k} \mathrm{k})(\mathrm{e} \mathrm{e} e)(\mathrm{t} \mathrm{t} \mathrm{t})$ & $* !$ & \\
\hline b. & $(\mathrm{k} \mathrm{k} \mathrm{k)}(\mathrm{e} \mathrm{e} \mathrm{e}) .(\mathrm{t} \mathrm{t} \mathrm{t}) \mathrm{e}$ & & $*$ \\
\hline c. & $(\mathrm{k} \mathrm{k} \mathrm{k})(\mathrm{e} \mathrm{e} \mathrm{e}) .(\mathrm{t} \mathrm{t} \mathrm{t})(\mathrm{e} \mathrm{e})$ & & $* * !$ \\
\hline d. & $(\mathrm{k} \mathrm{k} \mathrm{k})(\mathrm{e} \mathrm{e} \mathrm{e}) .(\mathrm{t} \mathrm{t} \mathrm{t})(\mathrm{e} \mathrm{e} \mathrm{e})$ & & $* * ! *$ \\
\hline e. & $(\mathrm{k} \mathrm{k} \mathrm{k})(\mathrm{e} \mathrm{e} \mathrm{e}) .(\mathrm{t} \mathrm{t} \mathrm{t})(\mathrm{e} \mathrm{e} \mathrm{e} \mathrm{e})$ & & $* * ! * *$ \\
\hline
\end{tabular}

Table 4: Violations of DEP-q constraint for candidates containing vowels with 1, 2, 3, and 4 subsegments

A similar prediction can be made by scaling MAX violations by the number of subsegments involved. Such an account makes it less costly to delete a light vowel than a long vowel, corresponding to the well-known effect that long vowels tend to be preserved, and short vowels are more readily elided.

By scaling faithfulness violations to the number of affected subsegments, Q Theory is able to generate the tendency for vowel strength to correlate positively with lexical status. However, the dimensions of strength and lexical status are still intentionally independent; the effects of subsegmentally scaled faithfulness can be overridden. This built-in flexibility is necessary to account for reported cases in which these two properties of a vowel do not align. In Turkish, for example, [+high] epenthetic vowels pattern for all intents and purposes identically to full [+high] lexical vowels in terms of their participation in phonological processes, including stress assignment (e.g. /film/ -> filim 'film', with stressed epenthetic [i] (see e.g., Lewis 1967). By contrast, lexical [+high] vowels in Turkish, in word-final position, can be shortened and devoiced to the point of being virtually inaudible (see e.g., Jannedy 1995). Subsegmental quantity correlates with faithfulness all else being equal, but in specific local contexts, other factors can disrupt the default alignment of these two dimensions. 
6. Vowel strength and stressability. The method of scaling constraints by subsegmental quantity is amenable to a wide range of phonological phenomena. Having seen its effects in the faithfulness domain, we illustrate in this section the effects of subsegmental scaling of markedness constraints - specifically constraints involved in the determination of quantitysensitive stress assignment. We generate a factorial typology of segment strength and stressability, showing that the languages generated by the typology are all plausible metrical systems.

Cross-linguistic studies of quantity-sensitive stress assignment typically focus on syllable structure, lexical vowel status, and vowel quality. Heavy, or bimoraic, syllables are preferred as stress sites over light syllables. Some quantity-sensitive stress systems are specifically sensitive to long vowels; all else equal, closed syllables are often preferred to open syllables (for general overviews, see e.g., Allen 1973, Hyman 1977, McCarthy 1979, Hayes 1995, Gordon 1999). It has also been noted that epenthetic vowels are often dispreferred for stress assignment (e.g., Broselow 1999). ${ }^{2}$ Furthermore, vowel quality may also affect stress assignment, with schwa least preferred (see e.g., Cohn 1989) and low, i.e. more sonorous vowels, most preferred for stress assignment (e.g., De Lacy 2002, Crowhurst \& Michael 2005). All of these parameters conspire together to make certain segment types, which we can term 'strong', better hosts for stress than other, 'weak' segment types. In what follows, we will use the concept of segment strength to capture the range of segmental parameters affecting stress assignment.

Positional factors also influence stress assignment patterns. Morphological structure is often relevant; where some languages prefer to assign stress to roots over affixes or clitics; in other languages, particular affixation processes shift the location of stress (for overviews see e.g. Hayes 1995, Alderete 2001). Stress is frequently attracted to one particular edge of a word, and can be limited to occurring within a particular edge-based window which is anchored at a word edge (see e.g., Hayes 1995, Kager 2012). Locality conditions also obtain: Adjacent stressed syllables are often avoided $\left({ }^{*} \mathrm{CLASH}\right)$, as are adjacent unstressed syllables (*LAPSE) (Liberman 1975, Liberman \& Prince 1977, Prince 1983). All of these 'positional stress' parameters are affected by relative distance of a stressed syllable to some morphological or prosodic boundary, such as a morpheme or a word edge, or the relative distance of a stressed syllables to one another.

To show the effect of incorporating subsegmental quantity into a model of stress assignment, we simplify matters here by considering only two factors: segment strength and positional patterns favoring stress at right edge of a phonological word.

To operationalize right-aligned stress, we used the standard ALIGN-STRESS-RIGHT constraint (McCarthy \& Prince 1994, Kager 1999). As originally postulated, this is a scalar constraint, violated once by each syllable occurring between the stressed syllable and the right edge of the word.

(1) Align-Stress-Right: Assign one violation for each syllable at the right edge of the word that does not bear stress

To operationalize segment strength, we need constraints which will favor stress on vowels with more subsegments over stress on vowels with fewer subsegments. There are several

\footnotetext{
${ }^{2}$ This observation has been formalized by Alderete (1999) into the HEADDEP constraint ("Assign one violation for every segment in a prosodic head in the output that does not have a correspondent in the input"), which has the consequence of assigning one violation for every epenthetic vowel bearing stress in the output.
} 
formally equivalent ways to encode this pattern (see e.g. the PKPROM family of Kager and Prince \& Smolensky; here we use stringent constraints (de Lacy 2004) to capture the implication that lower strength vowels are dispreferred for stress relative to vowels with greater strength (2).

(2) *STRESS/v: Assign one violation for every vowel with one subsegment that bears stress

*STRESS/v, vv: Assign one violation for every vowel with one or two subsegments that bears stress

*STRESS/v, vv, vvv: Assign one violation for every vowel with one, two, or three subsegments that bears stress

*STRESS/v, vv, vvv, vvvv: Assign one violation for every vowel with one, two, three, or four subsegments that bears stress

Working with the constraints in (1) and (2), we used the language solver tool available in OT Help (Staubs et al. 2010) to generate an Optimality-Theoretic factorial typology assuming a classical model of Optimality Theory, with strictly ranked constraints. The factorial typology predicted four possible language types, all of which constitute plausible stress systems for natural languages. The relevant constraint rankings for each one of the four language types are presented below in (3)-(6), along with examples of languages that plausibly instantiate each one of the four types.

(3) ALIGN-STRESS-RIGHT $>>$ *STRESS/v, ${ }^{*}$ STRESS/v, vv, *STRESS/v, vv, vvv, ${ }^{* S T R E S S / v, ~ v v, ~}$ VVV, VVVV
a. Cvvvv.Cvvv.Cvv.' $\mathbf{C v}$
b. Cvvv.' Cvvv

(4)

*STRESS/v >> ALIGN-STRESS-RIGHT >> *STRESS/v, vv, *STRESS/v, vv, vvv, *STRESS/v, $\mathrm{VV}, \mathrm{vVv}, \mathrm{vVvV}$
a. Cvvvv.Cvvv.' $\mathbf{C v v} \cdot \mathrm{Cr}$
b. Cvvv.' Cvvv

(5)

*STRESS/v, *STRESS/v, vv >> ALIGN-STRESS-RIGHT >> *STRESS/v, vv, vvv, *STRESS/v, VV, VVV, VVVV
a. Cvvvv.' Crvvv.Cvv.Cv
b. Cvvv.' Cvvv

(6) *STRESS/v, *STRESS/v, vv, *STRESS/v, vv, vvv >> ALIGN-STRESS-RIGHT $>$ *STRESS/v, $\mathrm{VV}, \mathrm{vVv}, \mathrm{vVvV}$
a. 'Cvvvv.Cvvv.Cvv.Cv
b. Cvvv.' Cvvv 
The system in (3), in which ALIGN-STRESS-RIGHT outranks all quantity considerations, generates a fully quantity insensitive stress assignment pattern. Stress is invariably aligned to the right edge of the phonological word, regardless of vowel size; even a superlight vowel can be stressed, as schematized in $(3 a, b)$. A language that plausibly exhibits this is Turkish. Setting aside overriding morphological complications, Turkish has default word-final stress. As mentioned above, final high vowels in Turkish are subject to shortening and devoicing to the point of verging on inaudibility; nonetheless, they are able to bear default final word stress.

The constraint ranking in (6), generating the patterns schematized in (6ab), is the mirror pattern of (3); it is fully quantity sensitive. In a language of the type in (6), the heaviest vowel in a phonological word always attracts stress, regardless of its position within the word (6a). If two or more vowels tie in terms of being the heaviest vowel in the word, ALIGN-STRESS-RIGHT locates stress on the rightmost such vowel, as in (6b). Two languages that may be analyzed as exhibiting such exquisite quantity-sensitivity are Tahitian (see Bickmore 1995) and Nanti (see Crowhurst \& Michael 2005). ${ }^{3}$

The systems in (4) and (5) provide more interesting test cases for Q Theory than the relatively straightforward systems in (3) and (6), in that they involve a threshold cutoff where some (potentially inserted) vowels can bear stress, but others cannot. In languages of type (4), stress always falls on the rightmost vowel in a phonological word, unless that vowel is superlight (i.e. unless that vowel has a single subsegment). This partially quantity-sensitive system is exemplified in (4ab). Two languages that may be analyzed as exhibiting such a system are Mẽbêngôkre (Salanova \& Reis Silva 2010) and French (see Van Oostendorp (1999), and Durand \& Eychenne (2007), among others). Both Mebêngôkre and French are languages in which stress always falls on the last vowel of the word, unless that vowel is final and extremely short (superlight), as in the case of word-final schwa. ${ }^{4}$

In languages of type (5), stress always falls on the rightmost vowel in a phonological word, unless the rightmost vowel is superlight (i.e. has a single subsegment) or light (i.e. has two subsegments). These languages are partially quantity-sensitive in that stress always falls on the rightmost full (or long) vowel of a phonological word, though not fully quantity-sensitive, in that long vowels do not attract stress away from (non-long) full vowels. This partially quantitysensitive system is exemplified in $(5 \mathrm{a}, \mathrm{b})$, and is observed in Panãra. Its manifestation will be presented in fuller detail in the following section.

7. Case study: Panãra stress assignment and vowel strength distinctions. In this section, we provide a case study of the partially quantity-sensitive stress assignment system in (5), which relies on the four-way distinction in vowel strength in Panãra depicted above in Table 3. A full description of the phonology of Panãra, including an account of its metrical system, can be found in Lapierre (2019). For now it suffices to note that Panãra has a contrast between oral and nasal vowels, as well as a contrast in vowel length for 14 vowel qualities. We focus here on evidence that the stress system in Panãra is sensitive to vowel strength.

\footnotetext{
${ }^{3}$ Note that Nanti stress assignment is determined based on a number of additional factors, including presence or absence of a coda consonant and vowel quality, among others.

${ }^{4}$ Note that French has traditionally been analyzed as a languages in which word-final unstressed schwas are deleted; however, it has been argued that in modern-day French, these vowels are better analyzed as excrescent vowels inserted under certain prosodic conditions rather than as deleted vowels.
} 
Stress in Panãra is culminative, meaning that there is no more than one stressed syllable per phonological word. Stress is always assigned within a two syllable window at the right edge of the word, such that it always falls on the ultimate (7) or the penultimate syllable (8).
a. [pa]
arm
e. [nã.'su]]
deer
b. [pa:]
foot
f. [ko.ti.'ko]
village name
c. [so.'ti]
fox
g. [pr.ti.'ti]
anteater
d. $\left[\mathrm{ku} .{ }^{\prime} \mathrm{kr \varepsilon}\right]$
house
h. [tu.pa.ju.'rõ]
village name

(8)
a. ['pr:.ri] tree
e. [po.'po:.ti]
round
b. ['t $\varepsilon$ :.pi]
f. [pr.ri.'kja:.ti]
tree stump
c. ['so: ti]
g. [te.pa.'kri: .ti]
whale
d. [a.'prẽ:.pi] picture, spirit
h. [nãn.se.po.'ti:.ti] village name

As can be seen from the examples in (8), when stress falls on the penultimate syllable of the phonological word, the penultimate vowel is always lengthened, ${ }^{5}$ and the last vowel of the word is always $[\mathrm{i}] .^{6}$

The fact that the quality of unstressed final vowels is entirely predictable suggests that this vowel may be a weak segment within the grammar of the language. Lapierre (2019) argues that unstressed final vowels in Panãra are epenthetic, rescuing words which would otherwise end in approximants or obstruents. The only word-final codas permitted in Panãra are nasals, examples of which are provided in (9).

(9)
a. $[\mathrm{kaj}]$
basket
b. [twa.' tũm]
elderly woman

Weak word-final [i] is not observed when the relevant root attaches to the left of a morpheme beginning with another oral consonant, as can be seen by comparing (10a) and (10b) to $(8 \mathrm{~b})$ and (8c), respectively. By contrast, stressed word-final [i] does not disappear under morpheme concatenation, as shown in (11).
(10) a./tep+pã:/ $\rightarrow$ [tep.'pã:]
small fish
b. /sot+pjo/ $\rightarrow$ [sop.'pjo]
nothing
(11)a. /soti+pã:/ $\rightarrow$ [so.ti.'pã:]
small fox
b./prtiti+pjo/ $\rightarrow$ [pr.ti.ti.'pjo]
small anteater

[i] serves as an epenthetic vowel in other parts of the phonology of Panãra. Specifically, word-initial [i] is an epenthetic vowel that serves to resyllabify phonologically long consonants

\footnotetext{
${ }^{5}$ Given that penultimate vowel lengthening has no bearing on the subsegmental analysis that we propose here for Panãra vowels, we do not discuss this process any further.

${ }^{6}$ The quality of this vowel is [u] if the preceding VC sequence is /op/ or /op/.
} 
(namely $\mathrm{NTs}^{7}$ and geminates) in word-initial position, as in (12). Note that epenthetic [i] is phonetically nasalized when it occurs before a nasal consonant.
(12) a./nnã/ $\rightarrow$ [ĩn.'nã]
fat
b. /nja+nnã/ $\rightarrow$ [ĩn.kjan.'nã]
fat paca
c. /nje:/ $\rightarrow$ [ĩ̃.'kje:
woman
d. /panãra+nje:/ $\rightarrow$ [pa.nã.ray.'kje:]
Panãra woman

Word-final epenthetic vowels in Panãra are weak: they cannot bear stress, and they show a limited set of vowel qualities, namely [i] and [u]. We model this behavior by representing them as two subsegments, distinguishing them representationally from both full and long vowels.

(13) $/ \mathrm{t} \varepsilon \mathrm{p} / \rightarrow[$ 't $\varepsilon: . \mathrm{pi}]$

fish

$$
\text { '(t t t ) }(\varepsilon \varepsilon \varepsilon) .(\mathrm{p} \mathrm{p} \mathrm{p})(\mathbf{i} \mathbf{i})
$$

The fact that long vowels are not preferred in assigning stress is exemplified below, in (14). This data provides clear evidence that a fully weight-sensitive system cannot capture the facts of Panãra stress.
(14) a./pa $:+\mathrm{kr} / \rightarrow\left[\mathrm{pa}: .{ }^{\prime} \mathrm{kr}\right]$
shoe
$(\mathrm{p} \mathrm{p} \mathrm{p})(\mathrm{a} a \mathrm{a} a) . '(\mathrm{k} \mathrm{k} \mathrm{k})(\boldsymbol{r} \boldsymbol{\gamma} \boldsymbol{\gamma})$
b. /ku:per/ $\rightarrow$ [ku:.'pe.ri]
proper name
$(\mathrm{k} \mathrm{k} \mathrm{k})(\mathrm{u} \mathrm{u} \mathrm{u} \mathrm{u})$. '(p p p) (e e e) . (r r) (i i )

To summarize, Panãra exhibits a four-way distinction in vowel quantity, with vowels ranging from one to four subsegments depending on their level of activation within the grammar of the language. In permitting full and long vowels, but not light vowels, to bear stress, Panãra exemplifies language type (5). Admittedly, it is not possible for us to test whether or not excrescent vowels in Panãra can bear stress, as excrescent vowels only arise on onset clusters. As such, they are always followed by a full vowel in nucleus position of the relevant syllable, which hosts lexical stress. However, given that excrescent vowels in Panãra cannot serve as the head of a syllable, it seems reasonable to us to assume that even if phonotactic considerations of the language did make word-final excrescent vowels possible, these vowels would still not be able to bear stress.

8. Discussion. Q Theory proposes quantized subsegmental representations that draw on Autosegmental Phonology, Aperture Theory, and Articulatory Phonology. Previous work on Q Theory has motivated the need for greater than binary granularity in subsegmental representations and has drawn parallels between Articulatory Phonology and Q Theory, proposing an analogy to articulatory landmarks in representing some segments such as aspirated stops, unreleased stops, flaps, and geminates. This paper builds upon previous work to propose subsegmental representations that capture segment strength and phonological status. In offering a scale of vowel quantity that goes beyond binary distinctions between 'short' and 'long', Q Theory joins a

\footnotetext{
${ }^{7}$ NTs arise from a phonological process whereby nasal consonants become post-oralized and devoiced before phonemically oral vowels and approximants.
} 
larger body of research into scalar segment strength, including the subphonemic features of Lionnet 2016 and the symbolic strength scales of Inkelas 2015, Sande 2017, Smolensky \& Goldrick 2017. Q Theory differs from these in representing strength in quantitative vs. qualitative terms.

Q-Theoretic representations are naturally allied with the gestural scores of Articulatory Phonology; both represent segments as events over time. Q-Theoretic representations are distinct in being quantized representations, a property which makes them amenable to frameworks that operate over discrete symbols, such as Optimality Theory. This discreteness allows Q Theory to make finite and concrete predictions about cross-linguistic phonological typology, as illustrated by the factorial typology of quantity-sensitive stress systems discussed in section 5 .

As representational models of phonology have only recently begun to consider segment strength, it is still difficult to assess the appropriate level of granularity in subsegmental representations. However, a growing body of evidence suggests a relation between a segment's strength and its ability to bear certain phonological properties. As such, further research addressing not only stress assignment, but other phonological features as well, such as ability to bear tone, number of vowel quality contrasts, etc. The model presented here aims to open the door for questions such as these and to integrate models of segment strength into frameworks like Optimality Theory.

\section{References}

Alderete, John. 1999. Head dependence in stress-epenthesis interaction. In Ben Hermans \& Marc van Oostendorp (eds.), The derivational residue in phonological Optimality Theory. 29-50. Amsterdam: John Benjamins.

Alderete, John. 2001. Dominance effects as transderivational anti-faithfulness. Phonology 18 (2). 201-253. https://doi.org/10.1017/S0952675701004067.

Allen, W. Sidney. 1973. Accent and Rhythm. Cambridge: Cambridge University Press.

Bickmore, Lee. 1995. Refining and formalizing Tahitian stress placement algorithm. Oceanic Linguistics 34(2). 410-442. https://doi.org/10.2307/3623050.

Broselow, Ellen. 1999. Stress, epenthesis, and segment transformation in Selayarese loans. Proceedings of the Berkeley Linguistics Society 25(1). https://doi.org10.3765/bls.v25i1.1203.

Browman, Catherine P. \& Louis Goldstein. 1989. Articulatory Gestures as Phonological Units. Phonology 6(2). 201-251. https://doi.org/10.1017/S0952675700001019.

Browman, Catherine P. \& Louis Goldstein. 1990. Tiers in Articulatory Phonology, with some implications for casual speech. In John Kingston \& Mary Beckman (eds.), Papers in Laboratory Phonology I: Between the Grammar and Physics of Speech. 341-376. Cambridge: Cambridge University Press.

Browman, Catherine P. \& Louis Goldstein. 1992. Articulatory Phonology: an overview. Phonetica 49. 155-180. https://doi.org/10.1159/000261913.

Cohn, Abigail C. 1989. Stress in Indonesian and bracketing paradoxes. Natural language \& linguistic theory 7(2). 167-216. https://doi.org/10.1007/BF00138076.

Crowhurst, Megan \& Lev Michael. 2005. Iterative footing and prominence-driven stress in Nanti (Kampa). Language 81(1). 47-95. http://www.jstor.org/stable/4489854. 
de Lacy, Paul. 2002. The formal expression of markedness. Amherst, MA: University of Massachesetts, Amherst dissertation.

de Lacy, Paul. 2004. Markedness conflation in Optimality Theory. Phonology 21(2). 145https://doi.org/10.1017/S0952675704000193.

Durand, Jaques, \& Julien Eychenne. 2007. Remarks on schwa deletion and epenthesis in French. Proceedings of the $5^{\text {th }}$ Journees d'Etudes Linguistiques. 89-94.

Gafos, Adamantios I. 2002. A grammar of gestural coordination. Natural Language \& Linguistic Theory 20(2). 269-337. https://doi.org/10.1023/A:101494231.

Garvin, Karee; Lapierre, Myriam; Inkelas, Sharon. 2018. A Q-Theoretic approach to distinctive subsegmental timing. Proceedings of the Linguistic Society of America. 3(9) 1-13. https://doi.org/10.3765/plsa.v3i1.4330.

Gordon, Matthew. 1999. Stress and other weight-sensitive phenomena: Phonetics, phonology, and typology. Los Angelas, CA: University of California, Los Angelas dissertation.

Hall, Nancy E. 2003. Gestures and segments: Vowel intrusion as overlap. Amherst, MA: University of Massachusetts dissertation

Hall, Nancy E. 2006. Cross-linguistic patterns of vowel intrusion. Phonology 23(3): 387-429. https://doi.org/10.1017/S0952675706000996.

Hall, Nancy E. 2011. Vowel epenthesis. In Marc van Oostendorp, Colin J. Ewen, Elizabeth Hume \& Keren Rice (eds.) The Blackwell companion to phonology. 5 vols. Oxford: WileyBlackwell. pp. 1576-1596. https://doi.org/10.1002/9781444335262.wbctp0067.

Hayes, Bruce. 1995. Metrical stress theory: Principles and case studies. Chicago: University of Chicago Press.

Hyman, Larry. 1977. On the nature of linguistic stress. In Larry Hyman (ed.), Studies in stress and accent (SCOPIL 4). Los Angelas, CA: University of Southern California.

Inkelas, Sharon \& Stephanie S. Shih. 2013. Contour segments and tones in (sub)segmental Agreement by Correspondence. Handout from talk presented at mfm, University of Manchester, UK.

Inkelas, Sharon \& Stephanie S. Shih. 2014. Unstable surface correspondence as the source of local conspiracies. In Joyce Iyer \& Leland Kusmer (eds.), Proceedings of NELS 44. Volume 1. Amherst, MA: GLSA.

Inkelas, Sharon \& Stephanie S. Shih. 2016. Re-representing phonology: consequences of Q Theory. In Christopher Hammerly \& Brandon Prickett (eds.), Proceedings of the NELS 46. GLSA Publications.

Inkelas, Sharon. 2015. Confidence scales: a new approach to derived environment effects. In Yuchau Hsiao and Lian-Hee Wee (eds.), Capturing phonological shades within and across languages. 45-75. Newcastle upon Tyne: Cambridge Scholars Publishing.

Inkelas, Sharon \& Stephanie S. Shih. 2017. Looking into segments. In Karen Jesney, Charlie O'Hara, Caitlin Smith \& Rachel Walker (eds.), Proceedings of the 2016 Annual Meeting on Phonology. Washington, DC: Linguistic Society of America. https://doi.org/10.3765/amp.v4i0.3996.

Jannedy, Stefanie. 1995. Gestural phasing as an explanation for vowel devoicing in Turkish. OSU Working Papers in Linguistics 45. 56-84.

Kager, René. 1999. Optimality Theory. Cambridge: Cambridge University Press.

Kager, René. 2012. Stress in windows: Language typology and factorial typology. Lingua 122(13). https://doi.org/10.1016/j.lingua.2012.06.005.

Lapierre, Myriam. 2019. A phonological analysis of Panãra. Berkeley, CA: University of California qualifying paper. 
Liberman, Mark. 1975. The intonational system of English. Cambridge, MA: MIT dissertation.

Liberman, Mark \& Alan Prince. 1977. On stress and linguistic rhythm. Linguistic Inquiry 8. 249336.

Lewis, Geoffrey. 1967. Turkish grammar. Oxford: Oxford University Press.

Lionnet, Florian. 2016. Subphonemic teamwork: A typology and theory of cumulative coarticulatory effects in phonology. Berkeley, CA: University of California dissertation.

McCarthy, John. 1979. On stress and syllabification. Linguistic Inquiry 10. 443465.

Pycha, Anne. 2009. Lengthened affricates as a test case for the phonetics phonology interface. Journal of the International Phonetic Association 39(1). 1-31. https://doi.org/10.1017/S0025100308003666.

Pycha, Anne. 2010. A test case for the phonetics-phonology interface: Gemination restrictions in Hungarian. Phonology 27(1). 119-152. https://doi.org/10.1017/S0952675710000059.

Remijsen, Bert. 2013. Tonal alignment is contrastive in falling contours in Dinka. Language 89:297-327.

Salanova, Andrés \& Maria Amélia Reis Silva. 2010. Mebengokre (Kayapó). In Emilio Bonvini, Joëlle Busuttil \& Alain Peyraube (eds.), Dictionnaire des langues. 1531-1538. Paris: Presses Universitaires de France.

Sande, Hannah. 2017. Distributing morphologically conditioned phonology: Three case studies from Guébie. Berkeley, CA: University of California dissertation.

Shih, Stephanie S. \& Sharon Inkelas. 2014. A subsegmental correspondence approach to contour tone (dis)harmony patterns. In John Kingston, Claire Moore-Cantwell, Joe Pater \& Amanda Rysling (eds.), Proceedings of the 2013 Meeting on Phonology. Washington, DC: Linguistic Society of America. https://doi.org/10.3765/amp.v1i1.22.

Shih, Stephanie S. \& Sharon Inkelas. 2019. Autosegmental aims in surface optimizing phonology. Linguistic Inquiry 50(1). 137-196. https://doi.org/10.1162/ling_a_00304.

Smolensky, Paul \& Matthew Goldrick. 2016. Gradient symbolic representations in grammar: The case of French liaison. Ms. Rutgers Optimality Archive.

Staubs, Robert, Michael Becker, Christopher Potts, Patrick Pratt, John J. McCarthy \& Joe Pater. 2010. OT-Help 2.0. Software package. Amherst, MA: University of Massachusetts, Amherst

Steriade, Donca. 1993. Closure, release and nasal contours. In Marie Huffman \& Loren Trigo (eds.), Phonetics and Phonology 5: Nasals, nasalization and the velum. 401-470.

Steriade, Donca. 1994. Complex onsets as single segments. In Jennifer Cole \& Charles Kisseberth (eds.), Perspectives in phonology. 202-291. Stanford, CA: CSLI.

Storto, Luciana R. 1999. Aspects of Karitiana grammar. Cambridge, MA: MIT dissertation. Van Oostendorp, M. 1999. Schwa in phonological theory. Glot International.

Wiesemann, Ursula. 1972. Die phonologische und grammatische Struktur der Kaingang Sprache. The Hague: Mouton. 